\title{
PARENT DEPENDENT GENOTYPE $\times$ ENVIRONMENT INTERACTION IN CROSSES OF SPRING WHEAT
}

\author{
K. S. BAINS \\ Department of Plant Breeding, Punjab Agricultural University, Ludhiona 141004, India
}

Received 14.vi.75

\begin{abstract}
Summary
Genotype $\times$ environment interactions have been analysed for grain yield in parental and successive generations derived from crosses between them in spring wheat (Triticum aestivum L.em Thell.). Six parental lines were chosen for these crosses on the basis of their known linear regression on the additive environmental means, deviations from linearity and mean performance. Six crosses, two low $\times$ low, two low $\times$ high and two high $\times$ high were set up on the basis of the linear sensitivity of the parental lines to the additive environmental variation and $F_{2}, F_{3}$ and $F_{4}$ generations derived from each of them. Both the linear and non-linear components of the genotype $\times$ environment interaction of the advanced generation of each cross were clearly related to the corresponding components of their parents. There was also clear evidence for the segregation of genes controlling these two components of the interaction in the $F_{3}$ and $F_{4}$ generations of the crosses between parents contrasting for these properties but not in the $F_{3}$ and $F_{4}$ generations of the crosses between parents which were similar for these properties.

All aspects of the phenotype, including linear and non-linear sensitivity to environment, are under genetical control and can, therefore, be selected for in crosses between appropriately chosen parents.
\end{abstract}

\section{INTRODUCTION}

IN order to obtain unbiased estimates of the genetical components of variation it is essential to be able to detect genotype $\times$ environment interactions and to estimate their magnitude. This interaction can be detected and quantified by a purely statistical approach (Yates and Cochran, 1938; Finlay and Wilkinson, 1963; Eberhart and Russell, 1966) or by a biometrical genetical approach (Mather and Jones, 1958; Jinks and Stevens, 1959; Bucio-Alanis, 1966; Bucio-Alanis and Hill, 1966; Perkins and Jinks, 1968 a and $b$; Bucio Alanis, Perkins and Jinks, 1969). In the Eberhart and Russell (1966) approach the interaction of genotype with environment is a function of the linear response of the genotype to the additive environment and any remaining interaction is due to deviations from this linear regression slope. They defined both these linear $\left(\beta_{i}\right)$ and non-linear $\left(\bar{s}_{\delta_{i}}{ }^{2}\right)$ components as stability parameters. Perkins and Jinks (1968 $a$ and $b$ ), Bucio-Alanis, Perkins and Jinks (1969) and Paroda and Hayes (1971) observed that both of these components are subject to genetical control and are at least in part subject to different genetic systems. Our knowledge of the inheritance of these components is as yet limited to investigations with Nicotiana rustica reported by Bucio Alanis, Perkins and Jinks (1969). These authors showed that it was possible to accurately predict the linear function $\left(\beta_{i}\right)$ of advanced generations of a cross between pairs of pure breading lines from those observed in the parental and $F_{1}$ generations. This they achieved by partitioning the geno- 
type $\times$ environmental interactions into those involving additive effects of the genes and those involving dominance effects.

In the present paper we shall examine further the transmission of known degrees of linear and non-linear functions of the genotype $\times$ environment interactions among parental lines to the advanced generations derived from crosses among them.

\section{Materials AND Methods}

The six wheat (Triticum aestivum L. em Thell.) genotypes listed in table 1 were selected on the basis of their known performance for grain yield and the linear and non-linear components of their genotype $\times$ environment interactions. These are summarised in table 2. On the basis of these properties six crosses were made. Two of these crosses (C306 $\times$ Turkey 1316 and U.S.A. $252 \times$ Turkey 1316) are between pairs of parents with low sensitivities to the environment, i.e. low $\times$ low; two, Hornblende $\times$ Turkey 1316 and

TABLE 1

List of parental lines used in the crosses
Line Origin
India
a. $\mathrm{C} 306$
U.S.A.
b. Turkey 1316
U.S.A.
c. U.S.A. 252
Mexico
d. Sonora 64
e. Hornblende
Australia
f. Ukrainka
Russia
Brief details
Tall, good tillering, awned spikes, bold amber grains, medium early maturity
Tall, good tillering, awned spikes, bold red grains
Medium tall, awned small spikes with dense tip, bold red grains
Two-gene dwarf, moderate tillering, awned spikes, medium sized red grains, early maturity
Tall, thick and stiff stem, high tillering, awnless spikes, small red grains, very late maturity
Tall, high tillering, awnless spikes, small red grains

Ukrainka $\times$ Hornblende, are crosses between pairs of parents, one of which has a low sensitivity and the other a high sensitivity to the environment, i.e. low $\times$ high; and two, Sonora $64 \times$ Hornblende and Ukrainka $\times$ Hornblende, are crosses between pairs of parents with high sensitivities to the environment. For each of the six crosses $F_{2}, F_{3}$ and $F_{4}$ generations were obtained.

Two experiments were grown. The first consisted of duplicate rows of the parents, $10 \mathrm{~F}_{2}$ rows and $50 \mathrm{~F}_{3}$ progenies each derived from a single randomly chosen $\mathrm{F}_{2}$ parent for each of the six crosses. These were grown in each of four environments, three were sowings made at the normal time at Ludhiana, Abohan and Gurdaspur and the fourth was a late sowing at Ludhiana during the winter of 1967 . The plants were grown in $2 \cdot 10 \mathrm{~m}$ long rows with spacings of $30 \mathrm{~cm}$ between rows and $15 \mathrm{~cm}$ within rows.

The second experiment consisted of 50 families of the $F_{4}$ generation of each cross obtained by bulking the seed from individuals within each of the corresponding $\mathrm{F}_{3}$ families. This was sown during the winter of 1968 at Ludhiana at two different dates, 29th November and 27th December at two different densities with spacings of $30 \times 15 \mathrm{~cm}$ and $27 \times 10 \mathrm{~cm}$ with row lengths of $2 \cdot 10 \mathrm{~m}$ and $1.50 \mathrm{~m}$ respectively. 
Both the first and the second experiment were replicated three times in a compact family block design where the crosses were first randomised and then progenies within crosses were randomised. Grain yield in gm were recorded on eight plants chosen at random from each row and yield was expressed on a per plant basis before analysis.

TABLE 2

Known performance of the parental lines as observed in a previous investigation

$\begin{array}{cccc}\text { Line* } & \text { Comparative grain } & & \\ a & \text { yield } & \beta_{i} & \bar{s}_{\delta_{i}}{ }^{2} \\ b & \text { High } & \text { Low } & \text { Low } \\ c & \text { High } & \text { Low } & \text { Low } \\ d & \text { High } & \text { Low } & \text { Low } \\ e & \text { High } & \text { High } & \text { High } \\ f & \text { Low } & \text { High } & \text { High } \\ \text { Low } & \text { High } & \text { Low }\end{array}$

* $a$ to $f$ refer to the six parental lines as given in table 1 .

An estimate of the additive environmental component of variation $\left(e_{j}\right)$ was obtained separately for each of the parental, $F_{2}, F_{3}$ and $F_{4}$ generations as the mean of that generation in each environment. For the parental $\mathrm{F}_{2}$ and $F_{3}$ generations the same set of environments were used leading to very similar $e_{j}$ values for the different generations. For the $\mathrm{F}_{4}$ different environments were used but these generated a similar range of $e_{j}$ values. These $e_{j}$ components (tables 3 and 4 ) have been used to carry out the regression analysis on each generation separately.

\section{TABLE 3}

The additive environmental component $\mathrm{e}_{\mathrm{j}}$ used in the regression analysis in parental, $F_{2}$ and $F_{3}$ generations during winter 1967

$\begin{array}{lcccc}\text { Abohar } & \text { Gurdaspur } & \text { Sites } & \overbrace{\begin{array}{c}\text { Normal } \\ \text { sowing }\end{array}}^{\text {Ludhiana }} & \begin{array}{c}\text { Late } \\ \text { sowing }\end{array} \\ \text { Generation } & & & 2.96 & -2.75 \\ \text { Parental } & 3.71 & -3.92 & 4.09 & -2.90 \\ \mathrm{~F}_{2} & 2.85 & -4.04 & 2.72 & -2.87 \\ \mathrm{~F}_{3} & 2 \cdot 70 & -2.55 & & \end{array}$

TABLE 4

The additive environmental component $\mathrm{e}_{\mathrm{J}}$ used in the regression analysis in $F_{4}$ generation during winter 1968

\begin{tabular}{|c|c|c|c|c|}
\hline \multirow[b]{3}{*}{ Generation } & \multicolumn{4}{|c|}{ Sowing dates and spacing } \\
\hline & \multicolumn{2}{|c|}{ November 29} & \multicolumn{2}{|c|}{ December 27} \\
\hline & $30 \times 15 \mathrm{~cm}$ & $23 \times 10 \mathrm{~cm}$ & $30 \times 15 \mathrm{~cm}$ & $23 \times 10 \mathrm{~cm}$ \\
\hline $\mathrm{F}_{4}$ & $3 \cdot 86$ & -0.39 & -0.78 & $-2 \cdot 69$ \\
\hline
\end{tabular}


TABLE 5

Mean grain yield, additive-genetic component $\left(\mathrm{d}_{\mathrm{i}}\right)$ linear regression $\left(\beta_{\mathrm{i}}\right)$ and deviations from linear slope $\left(\overline{\mathrm{s}}_{\delta_{i}}{ }^{2}\right)$ for the six parental lines grown in four environments

\begin{tabular}{|c|c|c|c|c|}
\hline Line† & Mean & $d_{i}$ & $\beta_{i}$ & $\bar{s}_{\delta_{i}}{ }^{2}$ \\
\hline$a$ & $17 \cdot 29$ & $2 \cdot 81$ & $-0 \cdot 19^{*}$ & 1.49 \\
\hline$b$ & $16 \cdot 40$ & 1.92 & $-0.38^{*}$ & 0.37 \\
\hline$c$ & $15 \cdot 77$ & $1 \cdot 29$ & $-0 \cdot 26^{*}$ & $2 \cdot 30$ \\
\hline$d$ & $15 \cdot 73$ & $1 \cdot 25$ & $0.47 * *$ & $4 \cdot 40$ \\
\hline 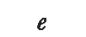 & $10 \cdot 07$ & $-4 \cdot 40$ & $0.38 * *$ & $6 \cdot 20$ \\
\hline$f$ & $11 \cdot 60$ & $-2 \cdot 87$ & $0.35 *$ & 0.23 \\
\hline
\end{tabular}
M.S.

* Probability $<0.001$ against error M.S. but non-significant against significant remainder

** Probability $<0.001$ against error M.S. and probability $<0.05$ against significant remainder M.S.

$\dagger a$ to $f$ refer to the six parental lines as given in table 1.

\section{Results}

(i) Parents

In table 5 are presented the mean grain yields and estimates of the components $d_{i}$, $\beta_{i}$ and $\vec{s}_{\delta_{i}}{ }^{2}$ for the six parents and the corresponding analysis of variance and joint regression analysis is summarised in table 6 . These confirm in all respects the description of the parents given in table 2 . The partitioning of the significant genotype $\times$ environment interaction sum of squares by the joint regression technique brings out clearly the justification for the earlier grouping of the parents. For example the three parents classified as having low linear sensitivities to the environmental variation (table 2) do not differ in their linear regressions (item 4, table 6). Equally, the three parents classified as having high linear sensitivities to the additive environmental variation also do not differ in their linear regressions (item 6 , table 6 ).

TABLE 6

Analysis of variance and joint regression analysis of the genotype $\times$ environment interaction for grain yield in six parental lines grown in four environments

Item

1. Genotypes

2. Environments

3. $\mathbf{G} \times \mathbf{E}$ interaction $\dagger(a) \mathrm{v}(b) \mathrm{v}(c)$

4. Het of Reg.

5. Remainder $(d) \mathrm{v}(e) \mathrm{v}(f)$

6. Het of Reg.

7. Remainder $(a, b, c) \vee(d, e, f)$

8. Het of Reg.

9. Remainder

10. Error

$\begin{array}{rrcc}\text { d.f. } & \text { M.S. } & \text { V.R. } & \ddagger \\ 5 & 34.06 & 38 \cdot 70^{* * *} & (10) \\ 3 & 106.09 & 120 \cdot 55^{* * *} & (10) \\ 15 & 6 \cdot 39 & 7 \cdot 26 * * * & (10) \\ & & & \\ 2 & 2 \cdot 49 & 0.32 & (5) \\ 4 & 7 \cdot 70 & 8 \cdot 75 * * * & (10) \\ & & & \\ 2 & 0.20 & 0.01 & (7) \\ 4 & 16.01 & 18 \cdot 19 * * * & (10) \\ & & & \\ 1 & 49.95 & 56 \cdot 76 * * * & (10) \\ 2 & 0.51 & 0.58 & (10) \\ 40 & 0.88 & - & -\end{array}$

*** $\mathrm{P}<0.001$.

$\dagger a$ to $f$ refer to the six parental lines as listed in table 1 .

‡ Item used as denominator in the variance ratio. 
There is, however, a highly significant difference in linear regression between the low and high groups (item 8, table 6). There are also significant nonlinear components of the genotype $\times$ environment interactions within both groups of parents that are more marked for the high than for the low group.

$$
\text { (ii) } F_{2}
$$

The corresponding analysis of the $\mathrm{F}_{2}$ 's of the six crosses is given in table 7 . On the basis of the parental properties the six crosses have been partitioned into three comparisons by the joint regression analysis by grouping the two crosses between a pair of low parents, the two crosses between a high and a

\section{TABLE 7}

Analysis of variance and joint regression analysis of the genotype $\times$ environment interaction for grain yield in the $F_{2}$ generation of six crosses grown in four environments.

\begin{tabular}{|c|c|c|c|c|}
\hline Item & d.f. & M.S. & V.R. & $\ddagger$ \\
\hline 1. Genotypes & 5 & $20 \cdot 87$ & $20 \cdot 46^{* * *}$ & $(12)$ \\
\hline 2. Environments & 3 & $99 \cdot 55$ & $97 \cdot 59 * * *$ & (12) \\
\hline $\begin{array}{r}\text { 3. } \mathrm{G} \times \mathrm{E} \text { interaction } \\
+(a \times b) \mathrm{v}(c \times b)\end{array}$ & 15 & $7 \cdot 17$ & $7 \cdot 03^{* * *}$ & (12) \\
\hline 4. Het of Reg. & 1 & 0.03 & - & (5) \\
\hline $\begin{array}{l}\text { 5. Remainder } \\
(e \times b) \vee(a \times e)\end{array}$ & 2 & $10 \cdot 22$ & $10 \cdot 02^{* * *}$ & (12) \\
\hline 6. Het of Reg. & 1 & $0 \cdot 20$ & - & $(7)$ \\
\hline $\begin{array}{l}\text { 7. Remainder } \\
(d \times e) \vee(f \times e)\end{array}$ & 2 & $16 \cdot 39$ & $16 \cdot 07 * * *$ & (12) \\
\hline 8. Het of Reg. & 1 & 0.05 & - & (9) \\
\hline 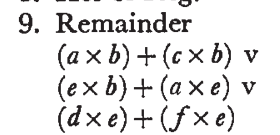 & 2 & $22 \cdot 74$ & $22 \cdot 29 * * *$ & (12) \\
\hline 10. Het of Reg. & 2 & $39 \cdot 95$ & $39 \cdot 16^{* * *}$ & (12) \\
\hline 11. Remainder & 4 & $2 \cdot 21$ & $2 \cdot 16$ & (12) \\
\hline 12. Error & 40 & $1 \cdot 02$ & - & - \\
\hline
\end{tabular}

low parent and the two crosses between a pair of high parents. Within each of these three sets of two crosses there are no significant differences between the linear regressions (items 4, 6 and 8, table 7) but there are very highly significant differences between the three sets (item 10, table 7). There are again significant non-linear components of the interactions within all three sets and these are once more larger for the crosses involving high parents.

$$
\text { (iii) } F_{3} \text { and } F_{4}
$$

In the $\mathrm{F}_{3}$ and $\mathrm{F}_{4}$ the partitioning of the genotype $\times$ environment interactions in the six crosses by the joint regression technique (Table 8 ) has been pushed even further by considering the 50 families of each cross separately. For each of the six crosses we have, therefore, a heterogeneity of linear regression sum of squares comparing the linear components of the 50 families and a remainder sum of squares testing the non-linear components. The pattern is quite clear and consistent. There are significant differences among 
the 50 families for their linear sensitivity to the environment within both the $F_{3}$ and $F_{4}$ generations only for those crosses where the parents differed in their sensitivities, one being high the other low. Where both parents were low, or both parents were high, all 50 families are homogeneous in their linear sensitivities in one or both generations. Furthermore, while the non-linear components do not conform to such a clearly predictable pattern, the only non-linear component that is highly significant in both the $F_{3}$ and $F_{4}$ is the one involving two parents both of which have high non-linear components.

TABLe 8

Analysis of variance and joint regression analysis of the genotype $\times$ environment interaction for grain yield in $F_{3}$ and $F_{4}$ generations of six crosses grown in four environments

\begin{tabular}{|c|c|c|c|c|c|c|c|}
\hline \multirow[b]{2}{*}{ Item } & \multirow[b]{2}{*}{ d.f. } & \multicolumn{3}{|c|}{$F_{3}$} & \multicolumn{3}{|c|}{$\mathrm{F}_{4}$} \\
\hline & & M.S. & V.R. & $\ddagger$ & M.S. & V.R. & $\ddagger$ \\
\hline 1. Genotypes & 299 & $46 \cdot 67$ & $10 \cdot 80 * * *$ & $(17)$ & $9 \cdot 56$ & $6 \cdot 45^{* * *}$ & (17) \\
\hline 2. Environments & 3 & $2959 \cdot 20$ & $685 \cdot 00 * * *$ & (17) & $2293 \cdot 03$ & $1549 \cdot 34 * * *$ & (17) \\
\hline $\begin{array}{l}\text { 3. } \mathrm{G} \times \mathrm{E} \text { interactio } \\
\dagger_{\dagger} a \times b\end{array}$ & on 897 & $7 \cdot 42$ & $1 \cdot 72 * * *$ & (17) & $2 \cdot 53$ & $1 \cdot 71 * * *$ & (17) \\
\hline 4. Het of Reg. & 49 & $5 \cdot 77$ & $0 \cdot 78$ & ( 5$)$ & $2 \cdot 04$ & $1.37 *$ & (17) \\
\hline 5. Remainder & 98 & $7 \cdot 36$ & $1 \cdot 70 * * *$ & (17) & 1.41 & 0.95 & (17) \\
\hline 6. Het of Reg. & 49 & 6.90 & $1 \cdot 11$ & ( 7 ) & $2 \cdot 26$ & $1.52 *$ & (17) \\
\hline 7. Remainder & 98 & $6 \cdot 18$ & $1.43 * *$ & (17) & 1.59 & 1.07 & (17) \\
\hline 8. Het of Reg. & 49 & $8 \cdot 00$ & $1 \cdot 85 * * *$ & (17) & $2 \cdot 95$ & $1.99 * * *$ & (17) \\
\hline $\begin{array}{l}\text { 9. Remainder } \\
a \times e\end{array}$ & 98 & $3 \cdot 77$ & $0 \cdot 87$ & (17) & $1 \cdot 12$ & $0 \cdot 76$ & (17) \\
\hline 10. Het of Reg. & 49 & $8 \cdot 53$ & $1.50 *$ & (11) & $2 \cdot 87$ & $1.93 * * *$ & (17) \\
\hline $\begin{array}{l}\text { 11. Remainder } \\
d \times e\end{array}$ & 98 & $5 \cdot 68$ & $1 \cdot 31^{*}$ & (17) & $1 \cdot 69$ & $1 \cdot 14$ & (17) \\
\hline 12. Het of Reg. & 49 & $5 \cdot 32$ & $0 \cdot 86$ & (13) & 2.09 & 1.01 & (13) \\
\hline $\begin{array}{l}\text { 13. Remainder } \\
f \times e\end{array}$ & 98 & $6 \cdot 22$ & $1 \cdot 44 * *$ & (17) & $2 \cdot 03$ & $1 \cdot 37 * *$ & (17) \\
\hline 14. Het of Reg. & 49 & $3 \cdot 85$ & 0.46 & (15) & $2 \cdot 04$ & 1.06 & (15) \\
\hline 15. Remainder & 98 & $8 \cdot 38$ & $1.94 * *$ & (17) & 1.91 & $1 \cdot 29 *$ & (17) \\
\hline 16. Crosses $\times$ Env. & 15 & $73 \cdot 04$ & $16 \cdot 91 * * *$ & (17) & $41 \cdot 12$ & $27 \cdot 78 * * *$ & (17) \\
\hline 17. Error & 2392 & $4 \cdot 32$ & & & $1 \cdot 48$ & & \\
\hline
\end{tabular}

Indeed, the only $\mathrm{F}_{4}$ 's showing a significant non-linear component had as one parent Hornblende which was the parent with the largest non-linear component (table 5).

Estimates of the three components $d_{i}, \beta_{i}$ and $\bar{s}_{\delta_{i}}{ }^{2}$ for each cross in the $\mathrm{F}_{2}$, $\mathrm{F}_{3}$ and $\mathrm{F}_{4}$ generations are summarised in table 9. These estimates leave no doubt that the differences in yield and in linear and non-linear environmental sensitivities among the six parents is consistently reflected in the properties of the advanced generations of the six crosses among them. It is also apparent that the negative correlation between mean performance $\left(d_{i}\right)$ and linear sensitivity $\left(\beta_{i}\right)$ shown by the parental lines (table 5) is also consistently maintained in the advanced generations. 
TABLE 9

Mean grain yield, additive-genetic component $\left(\mathrm{d}_{\mathrm{i}}\right)$, linear regression $\left(\beta_{\mathrm{i}}\right)$ and deviations from linear slope $\left(\overrightarrow{\mathrm{s}}_{\delta_{\mathrm{i}}}{ }^{2}\right)$ in successive generations of six crosses grown in four environments

\begin{tabular}{|c|c|c|c|c|}
\hline Cross $\uparrow$ & Mean & $\begin{array}{l}d_{i} \\
\text { (i) } \mathrm{F}_{2}\end{array}$ & $\beta_{i}$ & $\bar{s}_{\delta i}{ }^{2}$ \\
\hline$a \times b$ & $18 \cdot 78$ & $3 \cdot 03$ & $-0.51^{*}$ & $0 \cdot 10$ \\
\hline$c \times b$ & $17 \cdot 62$ & $1 \cdot 88$ & $-0 \cdot 64$ & $1 \cdot 60$ \\
\hline$e \times b$ & $13 \cdot 41$ & $-2 \cdot 27$ & $0 \cdot 22 *$ & $1 \cdot 02$ \\
\hline$a \times e$ & $15 \cdot 52$ & -0.23 & $0 \cdot 31 *$ & 1.06 \\
\hline$d \times e$ & $16 \cdot 07$ & 0.33 & $0 \cdot 44 *$ & $2 \cdot 12$ \\
\hline \multirow[t]{2}{*}{$f \times e$} & $13 \cdot 01$ & $-2 \cdot 74$ & $0 \cdot 48 *$ & $1 \cdot 67$ \\
\hline & & (ii) $\mathrm{F}_{3}$ & & \\
\hline$a \times b$ & $19 \cdot 01$ & $4 \cdot 39$ & -0.40 & $0 \cdot 74$ \\
\hline$c \times b$ & $18 \cdot 06$ & $3 \cdot 44$ & $-0 \cdot 60$ & 0.58 \\
\hline$e \times b$ & $11 \cdot 57$ & $-3 \cdot 05$ & $0 \cdot 15 *$ & 0.83 \\
\hline$a \times e$ & $13 \cdot 01$ & $-1 \cdot 61$ & $0 \cdot 17 *$ & $1 \cdot 10$ \\
\hline$d \times e$ & $14 \cdot 32$ & $-0 \cdot 30$ & $0 \cdot 21$ * & $2 \cdot 72$ \\
\hline \multirow[t]{2}{*}{$f \times e$} & $11 \cdot 75$ & $-2 \cdot 87$ & $0.47 *$ & $3 \cdot 60$ \\
\hline & & (iii) $\mathrm{F}_{4}$ & & \\
\hline$a \times b$ & $8 \cdot 67$ & $1 \cdot 70$ & $-0.31 *$ & $0 \cdot 03$ \\
\hline$c \times b$ & $8 \cdot 17$ & $1 \cdot 20$ & -0.44 & $0 \cdot 0$ \\
\hline$e \times b$ & $6 \cdot 16$ & $-0 \cdot 80$ & $0 \cdot 02 *$ & $0 \cdot 0$ \\
\hline$a \times e$ & $6 \cdot 71$ & $-0 \cdot 26$ & $0 \cdot 15 *$ & $0 \cdot 0$ \\
\hline$d \times e$ & $6 \cdot 51$ & -0.46 & $0 \cdot 16^{*}$ & $0 \cdot 3$ \\
\hline$f \times e$ & $5 \cdot 59$ & $-1 \cdot 38$ & $0.43 *$ & $0 \cdot 3$ \\
\hline
\end{tabular}
M.S.

* Probability $<0 \cdot 001$ against error M.S. but non-significant against significant remainder

$\dagger a$ to $f$ refer to the six parental lines as given in table 1 .

\section{INTERPRETATION}

Previous investigations of pure breeding lines and their $\mathrm{F}_{1}$ 's (Perkins and Jinks, $1968 a$ and $b$; Perkins, 1970; Paroda and Hayes, 1971) and in one instance the $\mathrm{F}_{2}$ and first backcross generations (Bucio Alanis, Perkins and Jinks, 1969) have shown that mean performance and linear and non-linear sensitivity to the environment are controlled at least in part by different genetical systems and that mean performance and linear sensitivity can be successfully predicted from one generation to another of the same cross. In the present investigation we have extended these findings to the $F_{3}$ and $F_{4}$ generations of six crosses which were chosen to contrast in their performances and in their linear and non-linear sensitivities.

Where both parents of the cross had either a high or a low linear sensitivity to the environment there was little evidence of segregation for differences in linear sensitivity among the $\mathrm{F}_{3}$ and $\mathrm{F}_{4}$ families from the same cross (figs. 1 and 2, $a \times b, c \times b, d \times e, f \times e)$. Furthermore, the average linear sensitivity of the $\mathrm{F}_{3}$ and $\mathrm{F}_{4}$ families corresponded completely with that of their parents. Only where the parents of a cross differed in sensitivity, one being high and the other low, was there clear evidence of segregation for differences in linear sensitivity, among the families of the $\mathrm{F}_{3}$ and $\mathrm{F}_{4}$ from the same cross (figs. 1 and 2,e $\times b$ and $a \times e$ ). Furthermore, this segregation was symmetrical around a mean value that corresponds with the mean of the parents of each 

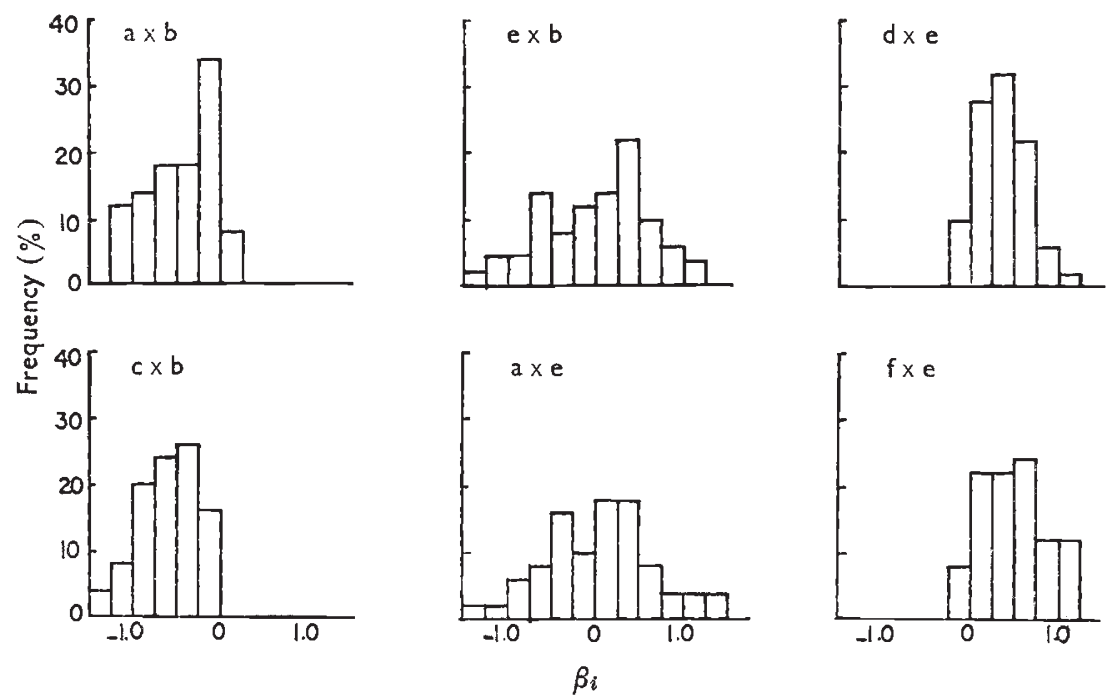

Fig. 1.-Distributions of the linear regression coefficients $\left(\beta_{i}\right)$ among the 50 families of the $F_{3}$ for each of the six crosses.
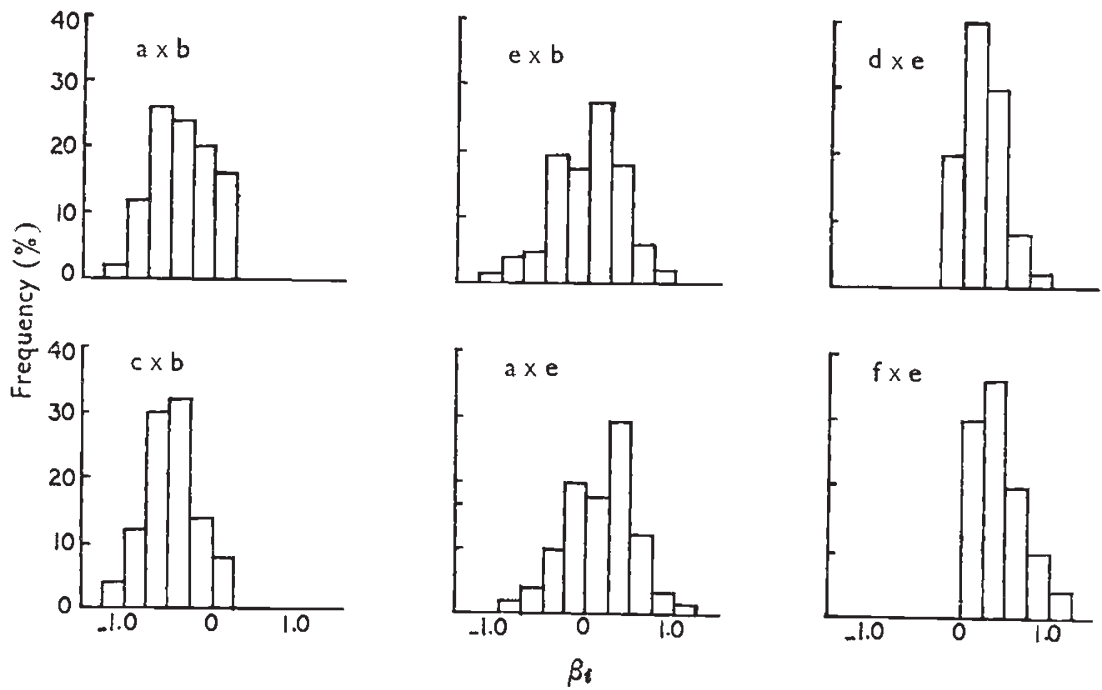

Fig. 2.-Distributions of the linear regression coefficients $\left(\beta_{\ell}\right)$ among the 50 families of the $\mathrm{F}_{4}$ for each of the six crosses.

cross. In respect of their relative performances and relative linear and nonlinear sensitivities to the environment, as well as in their patterns of segregation for sensitivity, the properties of the advanced generation of the six crosses are as expected from the corresponding properties of their parents. All aspects are clearly under genetical control and can, therefore, be selected for in crosses initiated from appropriately chosen parents. 
Acknowledgments.--I am indebted to Professor J. L. Jinks, Mr H. S. Pooni and Mr D. S. Virk for assisting in the interpretation of the results and the preparation of this paper; to Drs V. P. Gupta, B. S. Gill and D. S. Attwal for facilities and guidance.

\section{REFERENCES}

BUGIO-ALANIS, L. 1966. Environmental and genotype-environmental components of variability. I. Inbred Lines. Heredity, 21, 387-397.

BUGio-AlANIS, L., AND HILL, J. 1966. Environmental and genotype-environmental components of variability. II. Heterozygotes. Heredity, 21, 399-405.

BUCIO-ALANIS, L., PERKINS, JEAN M., AND JINKS, J. L. 1969. Environmental and genotypeenvironmental components of variability. V. Segregating generations. Heredity, 24, 115-127.

EBERHART, s. A., AND RUSSELL, w. A. 1966. Stability parameters for comparing varieties Crop Sci., 6, 36-40.

FINLAY, K. W., AND WILkINSON, G. N. 1963. The analysis of adaptation in a plant breeding programme. Aust. 7. Agric. Res., 14, 742-754.

Jinks, J. L., AND STEVENS, J. M. 1959. The components of variation among family means in diallel crosses. Genetics, 44, 297-308.

MATHER, K., AND JONES, R. MORLEY 1958. Interaction of environment in continuous variation. I. Description. Biometrics, 14, 343-359.

PARODA, R. S., AND HAYES, J. D. 1971. An investigation of genotype-environment interaction for rate of ear emergence in spring barley. Heredity, 26, 157-175.

PERKINS, JEAN M. 1970. Environmental and genotype-environmental components of variability. VI. Diallel sets of crosses. Heredity, 25, 29-40.

PERKINS, JEAN M., and JINKS, J. L. 1968a. Environmental and genotype-environmental components of variability. III. Multiple lines and crosses. Heredity, 23, 339-356.

PERKINS, JEAN M., and JINKS, J. L. 1968 $b$. Environmental and genotype-environmental components of variability. IV. Non-linear interactions for multiple inbred lines. Heredity, 23, 525-535.

yATES, F., and COchran, w. G. 1938. The analysis of groups of experiments. 7 . of Agric. Sci., 28, 556-580. 